\title{
EXISTENCE OF SOLUTION FOR FUNCTIONAL COUPLED SYSTEMS WITH FULL NONLINEAR TERMS AND APPLICATIONS TO A COUPLED MASS-SPRING MODEL
}

\author{
FELiz Minhós AND Robert DE SousA
}

\begin{abstract}
In this paper we consider some boundary value problems composed by coupled systems of second order differential equations with full nonlinearities and general functional boundary conditions verifying some monotone assumptions.

The arguments apply lower and upper solutions method and fixed point theory. Due to an adequate auxiliary problem, including a convenient truncature, there is no need of sign, bound, monotonicity or other growth assumptions on the nonlinearities, besides the Nagumo condition.

An application to a coupled mass-spring system with functional behavior at the final instant is shown.
\end{abstract}

Mathematics subject classification (2010): 34B15, 34B27, 34L30, 74H20.

Keywords and phrases: Coupled systems, functional boundary conditions, Green's functions, Schauder's fixed-point theorem, coupled mass-spring system.

\section{REFERENCES}

[1] Y. AN, Nonlinear perturbations of a coupled system of steady state suspension bridge equations, Nonlinear Analysis 51 (2002), 1285-1292.

[2] H. Amann, Parabolic evolution and nonlinear boundary conditions, J. Differential Equations 72 (1988), 201-269.

[3] R. ARIS, Introduction to the analysis of chemical reactors, Prentice-Hall, Englewood Cliffs, NJ, (1965).

[4] D. G. ARONSON, A comparison method for stability analysis of nonlinear parabolic problems, SIAM Rev. 20, (1978).

[5] N. A. Asif, P. W. Eloe, R. A. Khan, Positive solutions for a system of singular second order nonlocal boundary value problems, J. Korean Math. Soc. 47, 5 (2010), 985-1000.

[6] A. CABADA, F. Minhós, Fully nonlinear fourth-order equations with functional boundary conditions, J. Math. Anal. Appl. 340 (2008), 239-251.

[7] Y. CUI, J. SUN, On existence of positive solutions of coupled integral boundary value problems for a nonlinear singular superlinear differential system, Electron. J. Qual. Theory Differ. Equ. 41 (2012), $1-13$.

[8] T. H. Fay, S. D. Graham, Coupled spring equations, Int. J. Math. Educ. Sci. Technol., vol. 34, no. 1 (2003), 65-79.

[9] J. Graef, L. Kong, F. Minhós, J. Fialho, On the lower and upper solution method for higher order functional boundary value problems, Appl. Anal. Discrete Math., vol. 5, no. 1 (2011), 133-146.

[10] M. R. Grossinho, F. Minhós, A. I. SANTOS, A note on a class of problems for a higher order fully nonlinear equation under one sided Nagumo type condition, Nonlinear Anal. 70 (2009), 4027-4038.

[11] J. Henderson, R. LucA, Boundary Value Problems for Systems of Differential, Difference and Fractional Equations, Positive Solutions, Elsevier, 2015.

[12] J. Henders ON, R. LUCA, Positive solutions for systems of nonlinear second-order multipoint boundary value problems, Math. Meth. Appl. Sci. 37 (2014), 2502-2516. 
[13] G. Infante, F. M. Minhós, P. Pietramala, Non-negative solutions of systems of ODES with coupled boundary conditions, Communications in Nonlinear Science and Numerical Simulations 17 (2012), 4952-4960.

[14] T. JANKOWS KI, Nonnegative solutions to nonlocal boundary value problems for systems of secondorder differential equations dependent on the first-order derivatives, Nonlinear Analysis 87 (2013), 83-101.

[15] P. KANG, Z. WeI, Existence of positive solutions for systems of bending elastic beam equations, Electron. J. Differential Equations 19 (2012).

[16] A. LEUNG, A semilinear reaction-diffusion prey-predator system with nonlinear coupled boundary conditions: Equilibrium and Stability, Indiana Univ. Math. J. 31 (1982), 223-241.

[17] Y. LI, Y. GUO, G. LI, Existence of positive solutions for systems of nonlinear third-order differential equations, Commun Nonlinear Sci Numer Simulat 14 (2009), 3792-3797.

[18] H. LÜ, H. YU, Y. LIU, Positive solutions for singular boundary value problems of a coupled system of differential equations, J. Math. Anal. Appl. 302 (2005), 14-29.

[19] F. A. Mehmeti, S. NiCAise, Nonlinear interaction problems, Nonlinear Anal. 20, no. 1 (1993), $27-61$.

[20] F. Minhós, R. DE SousA, On the solvability of third-order three points systems of differential equations with dependence on the first derivatives, Bulletin of the Brazilian Mathematical Society, New Series, vol. 48, issue 3 (2017), 485-503.

[21] F. Minhós, I. Coxe, System of coupled clamped beam equations: existence and localization results, Nonlinear Analysis: Real World Applications 35 (2017), 45-60.

[22] F. Minhós, J. Fialho, On the solvability of some fourth-order equations with functional boundary conditions, Discrete Contin. Dyn. Syst., 2009, suppl., 564-573.

[23] I. TALIB, N. A. ASIF, C. TUNC, Coupled lower and upper solution approach for the existence of solutions of nonlinear coupled system with nonlinear coupled boundary conditions, Proyecciones Journal of Mathematics, vol. 35, no. 1 (2016), 99-117.

[24] J. YANG, Z. WEI, On existence of positive solutions of Sturm-Liouville boundary value problems for a nonlinear singular differential system, J. Appl. Math. Comput., 217 (2011), 6097-6104.

[25] F. YoRUK, N. AYKUT HAMAL, Second-order boundary value problems with integral boundary conditions on the real line, Electronic Journal of Differential Equations, vol. 2014 (2014), no. 19, pp. $1-13$.

[26] A. WAng, J. Sun, A. Zetth, The classification of self-adjoint boundary conditions: separated, coupled, J. Funct. Anal. 255 (2008), 1554-1573.

[27] E. ZeIDLER, Nonlinear Functional Analysis and Its Applications: Fixed-Point Theorems, Springer, New York (1986).

[28] F. ZHU, L. LIU, Y. WU, Positive solutions for systems of a nonlinear fourth-order singular semipositone boundary value problems, Applied Mathematics and Computation, 216 (2010), 448-457. 